\title{
Las Odas Seculares de Leopoldo Lugones
}

7 L centenario de la revolución de mayo fue celebrado por tres gran1 des poetas. Rubén Datío compone su "Cânto a la Argentina", Enrique Banchs su "Oda a los Padres de la Patria". Leopoldo Lugones escribe un libro: Odas seculares.

De los tres homenajes, sólo vive todavía en cuanto su sustancia poética alimenta algún modo de ser de la lírica argentina de nuestros días, y en cuanto la memoria nacional no lo ha alejado --como a tanta obra que parecía durable- de su cálida entraña, el de Leopoldo Lugones. El transcurso de medio siglo no ha envejecido la oda argentina; más de cincuenta años no han agotado su fértil depósito de poesía capaz de prestarse, de donarse - como en los grandes clásicos- - a las búsquedas líricas de las generaciones nuevas.

En las Odas seculares culmina el proceso lugoniano de objetivación poética que a partir del subjetivismo total, alucinatorio, de Las montañas del oro cristaliza, en concreciones de espesura diversa, en los libros intermedios: Los crepuisculos del jardín y Lunario sentimental.

En algunos momentos estas dos obras ingresan ya en cierto modo de prosaísmo realista que culminará en célebres pasajes de las Odas.

Nunca gocé ternura más extraña, que una tarde entre las manos prolijas del barbero de campaña, furtivo carbonario que tenía dos hijas.

dice en los Cnepuisculos, de 1905.

Muy luego ante su botella y' su rosbif, el joven pasajero 
se ha puesto a pensar —qué bueno- en una estrella cuando, de pronto un organito callejero viene a entristecerle la vida.

dirá en Lunario sentimental, de 1909.

Estos dos ejemplos, tal vez extremos en esos libros, demuestran sin embargo cómo ha quedado atrás la alucinante inmersión en las zonas del espíritu profundo expresada con las extraordinarias imágenes simbólicas, oniricas, supra-reales de Las montañas del oro.

En Los crepúsculos del jardín y en el Lunario sentimental, cada vez en un área mayor de ensanchamiento, lo cotidiano exterior, y aun interior, se va acercando, en su expresión, al llamado objetivismo plástico de las Odas seculares. Este libro significa, en relación con los anteriores, el momento en que la visión poética de Lugones se aproxima más a lo normal; el momento en que el lente ha sufrido una adecuación tal que permite la mayor naturalidad posible en la imagen de la realidad exterior próxima al eje. No es ya la visión pantográficamente desmesurada de inmensas criaturas que pueblan un universo entenebrecido por la culpa y el dolor de Las montañas del oro; ni la óptica impresionista, con trasposición equívoca de lo real al registro plástico, de Los crepúsculos del jardín; ni la doble visión del estrabismo realista-idealista convergente en los resultados de la ironía del Lunario sentimental. El cristal estético con que Lugones mira ahora la realidad exterior que se le presenta como un friso - ya veremos luego otras instancias-, no aumenta, no colorea, nunca deforma.

El libro apareció en 1910 con el propósito - como su título lo indica - de celebrar, con la noble dignidad clásica de la oda, el secular aniversario de la patria.

\footnotetext{
Patria, digo, y los versos de la oda como aclamantes brazos paralelos, te levantan Ilustre, Unica y Toda en unanimidad de almas y cielos.
}

La obra se articula orgánicamente en tres partes, cada una compuesta, a su vez, por series homogéneas de tres poemas. A la serie de "Las cosas útiles y magníficas" corresponden las composiciones de la geografía física y agtopecuaria; a la de "Las ciudades", las histórico-geográficas de las dos capitales platenses y Tucumán (esta última con un recuerdo alberdiano-sentimental de la Memoria descriptiva) y la de "Los hombres", los poemas legendario-evocativo-morales titulados: "A los gauchos", "Granaderos a caballo", "Los próceres". Como puede verse hay 
una composición premeditada en esta disposición de los materiales del libro que pretende modular en tonos distintos una vasta temática patriótico-celebratoria.

De los diez poemas que -incluida la introducción - componen la obra, el titulado "A los ganados y las mieses" es el que, a través de los años, sigue siendo memorable.

Este poema corresponde a un presente feliz de la patria, o, tal vez, al espejismo de esa felicidad. Se sustenta en la generosa visión de un infinito progreso agropecuario. Riqueza y trabajo, bienestar y paz para todos los hombres del mundo, están implícitos o explícitos en casi todos sus versos. Es éste, el contenido político y ético, digamos, que conviene a la celebración de la patria secular. Es lo que Lugones pudo decir en prosa; lo que en prosa se repitió, por entonces, incansablemente. La exaltación de las virtudes de un pueblo pastor y agrario que era dichoso o que, en el entusiasmo y la ebriedad conmemorativa creia serlo, fue su tema. La tradición literaria le ofrecia modelos milenarios. Y así, el gran poema celebratorio puede inscribirse en la línea de las tradiciones geórgicas. Carlos Obligado, en La cueva del fósil, cuando habla de este poema lo califica directamente de "argentinas geórgicas". Para una mejor comprensión, decimos que entenderemos aquí esta calificación virgiliana en un sentido muy general y de amplio espectro abarcador en cuanto posible género. En ella incluimos no sólo la poesía didáctico-rural de directa progrenie mantuana, sino también todos los matices bucólicos y arcádicos de la poesía descriptiva americana de signo clasicista.

La tradición geórgica, así entendida, se inició en América desde los primeros momentos de su literatura.

Guillermo Ara $^{1}$ remonta los antecedentes virgilianos de la oda a la poesía de Andrés Bello — piensa esde luego, en "A la agricultura de la zona tórrida"-; para los otros poemas indica, con alguna razón, a los neoclásicos argentinos. Concuerda el crítico con la opinión generalizada, pero creemos que los avatares del georgismo descriptivo del continente comenzaron mucho antes de que el poeta venezolano meditara en Londres la barroca enumeración tropical de sus afortunadas silvas.

Plasando por alto a algunos escritores del siglo xv, que podrian anotarse, aunque sólo fragmentariamente, en esta tradición - entre otros el celebrado Eugenio Salazar de Alarcón- nos encontramos ya en el siglo XVII, con una obra de alta calidad poética: La Grandeza mexicana de Bernardo de Balbuena, publicada en 1604. En ella ya se anuncia "A

1 Gụillermo Ara, Leopoldo Lugones (Buenos Aires: La Mandrágora, 1958). 
la agricultura en la zona tórrida', las odas argentinas y el último momento de esplendor de este género de poesía que creo debe encontrarse en La suave patria del mexicano López Velarde. Pero entre este gran poema del seiscientos y el que vamos a estudiar, se escalonan, en una misma vertiente genérica, aunque moduladas de distinto modo, numerosas obras emparentadas de alguna manera con la estirpe virgiliana. Citarcmos solamente aquéllas más significativas y de las que existe alguna posibilidad de que pudieran estar presentes en la gran erudición del Lugones de 1910.

Del jesuíta guatemalteco Rafael Landívar, que en el siglo xvil escribió en latín la Rusticatio mexicana, dijo Menéndez Pelayo": "La musa del P. Landívar es la de las Geórgicas, rejuvenecida y transportada a la naturaleza tropical". Esto basta para su ubicación en el "iso-georgismo" que, con su línea imaginaria, une distintos momentos y áreas distintas de la literatura hispano-americana. Pero no solamente agrega un punto más al dibujo de la geografía poética, sino que es - por sobre todo-- un punto significativo, único: en él se presenta, tanto en la lengua como en el cauce estilístico y formal virgiliano, un hecho nuevo y revolucionario: América.

Salve, cara Parens, dulcis Guatimala, salve

dice Landívar en lugar del

Salve, magna Parens frugum, saturnia tellus

de las Geórgicas latinas.

La obra de Landívar fue traducida por distintos autores, pero no conocemos ninguna versión completa, con anterioridad a las $O d d s$ seculares (Las traducciones completas del P. Federico Escobedo y de Ignacio Laureda son de 1924), y sí traslados más o menos libres de capítulos o fragmentos. Tanto los del poeta mexicano Fray Arcadio Pagaza como los del guatemalteco José Domingo Diéguez, pudieron - debieron- llegar al saber clásico y americano de Lugones. Pagaza utiliza la forma de la silva para su versión del canto I. En cambio José Domingo Diéguez emplea una forma métrica --endecasílabo asonantado- similar a la que casi dos siglos después utilizaría el poeta argentino. Nótese el tono de actualidad lugoneana -especialmente el verbo final tan repetido en las Odas- en este fragmento citado por Federico Hernández de León ${ }^{3}$ :

2 Marcelino Menéndez y Pelayo, Historia de la poesía bispanoamericana (Madrid: Consejo Superior de Investigaciones Científicas, 1948), I, p. 180.

3 Fedẹrico Hernández de León, Estudio sobre Landivar (Guatemala, 1932). 
Ya me parece que tus altos montes

a lo lejos mi vista determina,

a las praderas y campiñas verdes

que eterna primavera fertiliza.

El poemâ de Landívar está compuesto de quince cantos, más una Dedicatoria, una Advertencia y un Apéndice. Los tres primeros de los cantos propiamente dichos son legendario-geográficos. De los otros doce, ocho llevan los siguientes títulos, que cualquier lector de Bello y de Lugones sabrá ubicar en la correlatividad correspondiente: IV. "La cochinilla y la púrpura"; V. "El añil"; VII. "Las minas de plata y de oro"; IX. "E1 azúcar"; X. "Los ganados mayores" XI. "Los ganados menores"; XIII. "Las aves"; XIV. "Las fieras".

De uno de estos cantos dice Hernández de León: "No conocemos en la vasta literatura americana nada que se le asemeje en vigor y acierto. A veces se percibe el influjo de Virgilio, por lo que importa a la tendencia didáctica de las Geórgicas. Pero de súbito Landívar se sacude de todo influjo y se destaca con su propia personalidad, con su arrogancia, con su poder irresistible de hombre-cumbre". Esto quiere decir que se ha dado un paso más en la evolución del canto geórgico, dinamizado por el hecho revolucionario de América, hacia sus formas más modernas y modificadas. Así, la "maquinaria" del trapiche que aparece en las Odas seculares, tiene su antecedente en la Rusticatio, según esta versión en prosa: "Entra bajo el anchuroso techado de vasta circunferencia, en donde se levanta la poderosa máquina de gran mole, profundamente hincada en el suelo, con tres cilindros coronados de metal y de duro roble cortados".

¿No estamos en presencia de ese prosaísmo moderno de la "cosa" que se ha elogiado tanto $-y$ también rechazado- en las Odas seculares?

Poco diremos de Andrés Bello en este somero examen de precedentes. Generalmente se le considera como antecesor único y primordial. En 1827, en Londres se publicó la silva "A la agricultura de la zona tórrida". Sólo los cincuenta o sesenta primeros versos del extenso poema están dedicados a los productos de la tierra americana: el cacao, la cochinilla, el añil (como en Landívar), el vino, el tabaco, el ananás, Ia patata, el algodón y poco más.

Sin embargo, no hay descripción de ese mundo agrario con que Bello pretende atraer al rústico of icio a los jóvenes de aquella lejana post-guerra (la que sigue a Ayacucho). Simplemente enumera; decorativamente 
presenta un atractivo muestrario de acopiador poético de frutos de la tierra. Lo que sigue a esta inicial condensación agrícola es una larga moralización sostenida por el prestigio clásico del Beatus ille horaciano. Si se cita "A la agricultura de la zona tórrida" como antecednte lugoneano, también debe recordarse, $y$ concedérsele la misma importancia, a otro poema de Bello escrito unos años antes, en 1923: la "Alocución a la poesía". Esta composición anuncia el segundo poema, y al mismo Bello como a un nuevo Virgilio - prueba de que la tradición continúa- al vaticinar, en bien armados endecasílabos:

Tiempo vendrá, cuando de ti inspirado

Algín Marón americano, oh Diosas!

también las mieses, los rebaños cante...

Este poema, en menos de veinte versos, enumera comprimidamente los dones de la tierra americana levantados a la dignidad clásica y poética especialmente por el epíteto. En su posterior silva "A la agricultura de la zona tórrida", los complicará metafóricamente y los retorcerá en una flexión barroca.

De cualquier modo, no se puede negar que si el Bello de 1823 anunciaba al Bello de 1827, también profetizaba al cantor de las mieses y los rebaños argentinos. Asimismo podemos decir que el cantor de 1910 quiso ser, lúcidamente, el Marón anunciado en los lujosos endecasílabos que Bello dio a nuestras letras en 1823.

Otro poeta inscripto en las pautas de la poesía virgiliana-descriptiva del continente, es Fray Joaquín Arcadio Pagaza, mexicano que vivió entre 1839 y 1918, y por lo tanto coetáneo, en cierto modo, de Lugones. Creemos que el estudio de este escritor se hará imprescindible para quienes, con nuevos ojos, traten de comprender el complicado nacimiento del modernismo americano.

Fray Arcadio Pagaza, eminente latinista, traductor de Virgilio, de Horacio y de Landivar, entre muchas composiciones bucólicas y arcádicas, especialmente sonetos, y un extenso poema dialogado al modo de las bucólicas, titulado "Reto", también escribió una larga composición, "María", que subtituló "Poema descriptivo de las tierras calientes", publicado en 1890. En ella encontramos, como en Salazar de Alarcón, como en Bernardo de Balbuena, como en Landívar, como en Bello, la constate americana del georgismo: o sea el olvido, cada vez más notable, de la "paideia" ético-rural, en beneficio de lo descriptivo, de la consignación poética de la naturaleza cercana, local, pintoresca. 
La estrofa renacentista -octava real- empleada por Pagaza, no consigue aquietar, en el dibujo severo de la distribución rigurosa y nada brillante de las rimas, la agitación flamigera de un contenido barroco:

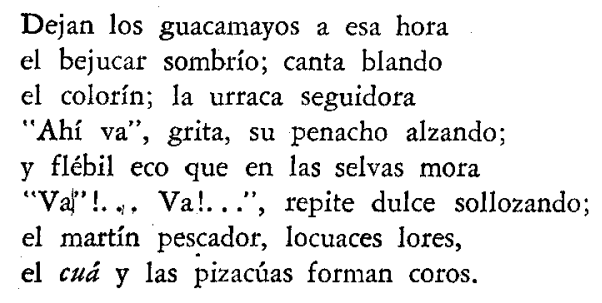

En ella colosal, que parda espuma baña y las piedras del humoso hornillo, hierve el café que el ámbito perfuma $\sin$ que le estorbe su color de ocrillo.

De la enumeración de los productos y bestias de la tierra, con sus cotrespondientes epítetos, se pasa enseguida a los hombres que la habitan, con sus costumbres, sus vestidos, su alimentación, sus diversiones, es decir una Summa Agrícola similar a la que treinta años después publicaría Lugones en Buenos Aires.

Son muchos los escritores americanos que de un modo u otro testimoniaron, más o menos extensamente, la realidad rural de sus países "sub specie poesiae". La simple enumeración de sus nombres resultaría excesiva y baldía. Sólo queremos, a los fines de nuestro interés concreto, recordar a un poeta más, que expresamente hemos dejado para el final porque su vinculación directa con Lugones nos parece mucho más visible.

En 1867 y en 1881 se publicaron las poesías del colombiano Gregorio Gutiérrez González. Entre ellas se encontraba el vasto poema agrícola que le dio celebridad y por el cual hoy se le recuerda: "Memoria sobre el cultivo del maíz en Antioquia". Este título, que parece de trabajo científico para ser presentado en un Ministerio de Agricultura, ampara a uno de los más extraordinarios poemas del continente. No me corresponde, en esta ocasión, examinarlo, sino simplemente darle ubicación en la trayectoria del georgismo americano en un área ya tangente a la del poeta argentino.

Para quienes recuerden las Odas seculares, no dejarán de serles familiares estos versos: 
Hoy es domingo. En el vecino pueblo las campanas con júbilo repican; del mercado en la plaza ya hormiguean los campesinos al salir de misa.

Hoy han resuelto los vecinos todos hacer a la patrona rogativa, para pedirle que el verano cese, pues lluvia ya las rosas necesitan.

Esta prosa vecinal es la de grandes momentos de la "Oda a los ganados y las mieses", la de la visita de don Pieri y su familia de "útiles gringuitos", por ejemplo, a un endomingado pueblito bonaerense o cordobés.

Pero hay algo más que el tono común y es la forma estrófica idéntica en el colombiano y en el argentino. Ambos prefieren el largo tomance endecasílabo asonante de una sola rima, con la diferencia de que Lugones la mantiene en toda la oda y Gutiérrez González la cambia en cada uno de los cantos.

Esta monotonía de lo unirrítmico y lo unirrimado, si bien reúne en un mismo esquema auditivo a las dos extensas composiciones, no bastaría para evocar la una por la otra, si no se tocaran en zona común por una misma temática y especialmente por una misma voluntad de estilo: el realismo diferenciado o traspuesto; el realismo enmarcado estéticamente, $y$, sin miedo a la palabra, artificiosamente.

Bastarán unos pocos ejemplos tomados del Canto III de la "Memoria", los que se refieren al maíz:

¿Qué bello es el maíz! Mas la costumbre no nos deja admirar su bizarría, ni agradecer al cielo ese presente, sólo porque lo da todos los días.

Contemplad una mata. A cada lado de su caña robusta y amarilla penden sus tiernas hojas arqueadas, por el ambiente juguetón mecidas.

$\mathrm{Su}$ pie desnudo los anillos muestra que a trecho igual sobre sus nudos brillan y racimos de dedos elegantes en los cuales parece que se empina...

Se despliegan al sol y se levantan ya doradas, temblando las espigas, que sobresalen cual penachos jaldas de un escuadrón en las revueltas filas. 
Brota el blondo cabello del filote que muellemente al despertar se inclina; el manso viento con su hebra juega y ell cariñoso sol los tuesta y riza.

Los pericos en círculo volando en caprichosas espirales giran dando al sol su plumaje de esmeralda y al aire su salvaje algarabía.

$Y$ sobre el verde manto de la rosa el amarillo de los techos brilla cual onzas de oro en la carpeta verde de una mesa de juego repartida.

No se trata de calco directo, ni de mera imitación. Apenas podrían señalarse coincidencias de detalle. En su alabanza al maíz, Lugones dice: "Cantemos al maíz cuyo tesoro..." y Gutiérrez González: "Qué bello es el maíz, ese presente..." Lugones: "Sobre la estrella de rayada chala..." el colombiano recurre a la misma metáfora: "Salpicado de estrellas de esmeralda.. ." Lo demás, lo parecido, es actitud similar ante la naturaleza. Al fin de la tradición virgiliana de América, Lugones se encuentra con un gran poema que, en cierto modo, anticipa una de las laderas por las cuales se deslizará el modernismo posterior a Prosas profanas y Cantos de vida y esperanza. Y, si la "Memoria del cultivo del maíz en Antioquia" no le sirve de modelo, sí se ofrece como ejemplo de lo que puede ser una actualización de los carmina virgilianos.

Acepta su métrica, su prosaísmo esteticista, el movimiento de su sintaxis. $Y$ el poeta argentino, que en sus tres libros anteriores habia asimilado, en tumultuoso y espléndido trofismo, a Hugo, Baudelaire, Rimbaud, Samain, Lautréamont, Poe, Whitman, Dante, la Biblia, radiça su poesía celebratoria de 1910 en la secular tradición geórgico-descriptiva de América, bajo el signo de un poeta que anuncia el modernismo de temática continental en su gran poema colombiano.

La mayor densidad metafórica del argentino no establece una diferencia de naturaleza o estilo entre uno y otro poeta, sino un mero dosaje acumulativo. En los cincuenta años que los separan, la poesía universal ha transformado, en revolución permanente, los postulados burgueses del siglo $\mathrm{xrx}$.

Alguna diferencia debe existir entre una poesía anterior a Baudelaire, Rimbaud, Lautréamont y los demás creadores del gran lirismo contem- 
poránea, y otra que, aun a pesar de retornar a una tradición secular, había pasado ya por el incendio de la revolución estética.

Ya hemos dicho que la "Oda a los ganados y las mieses" es la expresión de una edad feliz de la patria o su piadoso simulacro. Lugones se propuso censar, en productos y hombres, esa felicidad. Trató de disponer, en articulación coherente y a través de una estética del ojo, cuadros y escenas campesinos, junto a la alabanza, a la celebración ética y al epos pampeano. Su poema es la versión del optimismo y la ebriedad progresista de 1910. Las mieses y los ganados sustentan una riqueza que no ha de agotarse jamás. Hombres venidos de todos los climas del mundo crean esa riqueza y participan de ella por derecho conquistado. La edad dorada no es el tiempo pasado, es este presente en que todas las naciones del mundo saludan a la gran patria del Plata. La Argentina no es la esperanza sino la realidad de pampas infinitas arrebatadas a la soledad y la distancia para producir prosperidad sin término, majestuosa justicia y sostenida paz.

Esto fue lo que quiso cantar, lo que cantó en memorables endecasílabos. Pero había algo más, como luego veremos. A este optimismo se acomoda la visión, por primera vez plácida desde Las montañas del oro, aunque a veces arrebatada por el entusiasmo. $Y$ esa placidez tiene su correspondencia estilística. Desaparecen todos los elementos que en el libro anterior, el Lunario sentimental, significaban el espíritu en crisis y su expresión irónica. El verso libre, y en especial el acento libre dentro del verso, la rima insólita, burlesca, el vocabulario farmacéutico, científico, la metáfora sorprendente apenas sostenida en un mínimo tertius comparationis del Lunario, se transforma en las $O d a s$ en una fluencia rítmica serena, en la modestia de la rima asonantada, algunas veces en la clásica exaltación del epíteto, en una visión más directa y menos metafórica de la realidad inmediata. A la desaforada imaginería lunar sucede una placentera estadística poética de las cosas terrestres.

Estamos frente a una poesía que se ha llamado descriptiva, es decir, frente a un arte que aspira a ser objetivo. Más adelante hemos de ver cómo esta afirmación que se repite cuando se habla de la "Oda a los ganados y las mieses", no basta por sí sola para explicar todo el largo poema.

\section{LA VISUALIDAD}

La "Oda" comienza con una extendida mirada panorámica de los campos sembrados: 


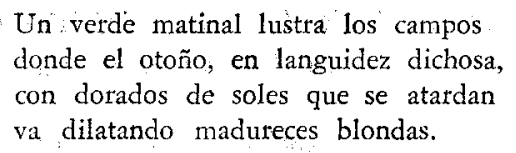

Toda una gama, no sólo de colores, sino de matices de lo verde, lo dorado y de la luz. El ojo se impresiona sin determinar todavía un punto de referencia. Sólo el primer verso es descriptivo. Los otros son explicativos, como lo prueba el plural soles, que no corresponde a lo visto - se ve un sol, este sol- sino al depósito de la memoria que gencraliza.

...va dilatando madureces.

El verbo sintagmático - -ir más gerundio- de lentísimo avance, no se refiere a este momento del mirar, sino a un proceso comenzado mucho antes y que se continúa. Tampoco el sustantivo plural "madureces" significa esta, aquella y aquella otra madurez, sino que menta un hecho genérico: la madurez - sustantivo abstracto- de los campos en otoño.

No pretendemos realizar un examen estilístico de la "Oda", que nos demandaría numerosas páginas, sino simplemente explicar cómo, desde el comienzo, lo descriptivo no se da de la manera franca que siempre se había creido; cómo las "Odas" no son un catálogo ordenado de lo que el ojo ve impasiblemente y cómo, sí, cada referencia al paisaje está rodeada de aureolas interiores que lo arrancan de su contexo objetivo para categorizarlo estéticamente.

La repetición de este procedimiento nos hará entender, entonces, que el mentado objetivismo de las "Odas" no es siempre el del mero realismo. Que su naturaleza intima es distinta a la del fatigoso censismo óptico. Sin embargo, en toda la primera parte el descriptivismo objetivo avanza caudalosamente sobre las instancias menos realistas y domina los planos expresivos. Pero pronto la aparición de la interioridad, con una pasión cada vez más intensa obrando sobre la tendencia descriptiva, nos dará el verdadero rostro del poema, en un doble juego confluente o divergente según las ocasiones de objetividad y subjetividad.

Pero continuemos con esa primera parte, tal vez la más ortodoxamente descriptiva de la composición. A los cuatro versos ya considerados siguen estos otros:

\footnotetext{
A través de la Pampa, un río turbio de fertilidad, rueda silenciosa

su agua que tiene por modesta fuente

la urna de tierra de la tribu autóctona.
} 
La claridad ricamente matizada del paisaje inicial está cruzada ahora por la oscura y lenta marcha de un río, que representa, en el juego simbólico, la materna naturaleza indígena.

En el Lugones de las "Odas" sobrevive, o más bien reaparece - tal vez retóricamente- el mito de la raza solar que está en los dos modelos celebratorios que podía tener presentes: el canto a "La batalla de Junio", de Olmedo y las estrofas del "Himno nacional", de Vicente López y Planes, del que había calcado, con pocas variantes, la primera estrofa para su "Canto a Buenos Aires".

$$
\begin{aligned}
& \text { Se conmueven del Inca las tumbas } \\
& \text { y en sus huesos revive el ardor } \\
& \text { lo que ve renovado en sus hijos } \\
& \text { de la Patria el antiguo esplendor. }
\end{aligned}
$$

En más de una ocasión, en los distintos poemas de las Odar seculares, la remisión retórica a los orígenes incaicos y al mito solar sugieren un telurismo indígena que acaso Lugones no sintió íntimamente. Por ejemplo, en su "Poema del Plata" dice:

\section{Moreno como un Inca, la excelencia de la raza solar te impone el cetro.}

Este tono oscuro de la raza solar es el que atraviesa la áurea claridad trabajada por los gringos, de las mieses pampeanas.

\section{de fertilidad...}

$$
\text { ...un río turbio }
$$

Es decir, la oscura entraña materna indígena que permite las "madureces blondas" de los trigales. ( $\mathrm{Y}$, al paso, notemos cómo el encabalgamiento del verso se ajusta al meandro, al lento fluir del espeso río natal.)

Turbio, urna de tierra, tribu autóctona, imponen una gama oscura, terrestre, genésica, al colorismo apacible, benévolo del poema.

De los seis versos siguientes sólo el primero es descriptivo:

Negrea un monte en la extensión...

Ese verbo de color negrear, pertenece al más franco repertorio impresionista, posee un dinamismo que hace vibrar toda la línea y, por primera vez, sugiere el ancho paisaje viviente, exterior; pero los versos que le siguen con sus felices metáforas -el agua azul del horizonte, la fresca 
bandera de la sombra- como en el caso anterior, comprometen de memoria personal, de saber, de interioridad, la independencia de la visión impecable del objeto.

$$
\begin{aligned}
& \text { Y mientras desde la invisible estancia } \\
& \text { algún gallo los campos alboroza, } \\
& \text { aventando su ráfaga de hierro } \\
& \text { el recio tren las extensiones corta. }
\end{aligned}
$$

Con estos versos termina la primera estrofa. Un examen estilístico, que no pensamos hacer ni en detalle ni en rigor, nos mostraría cómo los dos versos finales rompen estrepitosamente la inmovilidad contemplativa. En primer lugar se nos contrapone - ruptura viỏlenta, vértigo- el apenas audible canto del gallo en la invisible estancia y el estruendo del tren lanzado a toda velocidad por los callados campos. El verbo aventar con su connotación de violencia, los fonemas vibrantes de ráfaga, bierro, recio, tren, con su chirtiar violento; el esdrújlo que imprime velocidad al ver. so y apoya la acentuación anapéstica inicial; la anticipación del comple. mento de modo - arrastrando su ráfaga de hierro- al sujeto y el complemento directo - $\mathrm{el}$ recio tren las extensiones corta-, anticipación que admirablemente sugiere el estruendo y la fuerza de la locomotora encabezando, al frente del convoy, la serie de vagones que le sigue. Estos dos versos señalan el momento en que la oda comienza a moverse, en que el eje comienza a desplazarse a lo largo de su itinerario óptico. Y este deslizamiento se realiará según un variadísimo juego de enfoques. La cámara paseará su lente panorámicamente o lo fijará en un detalle alejado del paisaje, o en otro más cercano, o se aproximará a pocos metros para analizar magníficos detalles en un prodigioso primer plano. Jugará con la movilidad o con el estatismo plástico en un despliegue de extraordinario instrumental estilístico.

La visión, hasta ahora, ha sido panorámica. El ojo se ha desplazado desde una cercanía no inmediata hacia la lejanía del horizonte (no alcanza, sin embargo, la perspectiva aérea, notable en algunos poemas de los Crepúsculos del jardín, su libro más pictórico), pero no se ha fijado en ningún punto, en ningún objeto determinado. La oda está construida, por lo menos en esta primera parte, de acuerdo a un plan de visualidad que se cumple en tres etapas: a) la visión panorámica que hemos visto hasta ahora; b) la fijación del movimiento de la mirada en un punto determinado del paisaje y $\mathfrak{c}$ ) : un brusco acercamiento del eje -primer planoa ese punto y su descripción detallada y morosa. 
Las dos etapas finales se cumplen a continuación de los versos que hemos ya considerado. Continúa el poema:

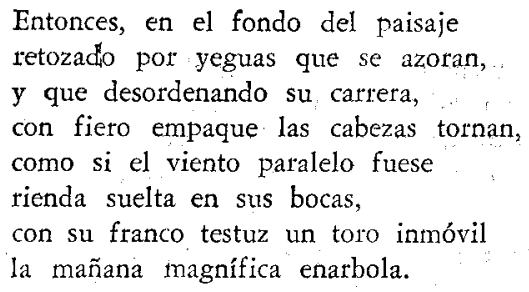

Es la segunda estrofa del canto. Si la reordenamos sintácticamente, suprimiendo los complementos secundarios y, en una palabra, la despoetizamos, dice lo siguiente: Entonces, un toro inmóvil enarbola la mañana magnífica con su franco testuz en el fondo del paisaje.

El cuadro está ubicado, no en la cercanía inmediata, sino en el fondo del paisaje. Además, el desplazamiento visual —nada nos impide pensar que la visión panorámica es la que se ofrece desde la ventanilla del tren-se ha detenido en un punto de ese paisaje: el toro inmóvil. Es el procedimiento cinematográfico de suspender la sucesión de las imágenes y fijar en la pantalla una fotografía sin movimiento.

Pero no solamente es en los dos últimos versos donde se consigue esa fijación óptica, ni ésta está dada en su totalidad por el adjetivo inmóvil que directamente alude a quietud. Desde su comienzo se ha puesto en movimiento un diapositivo estilístico que culminará en la imagen estética, El inocente adverbio de tiempo, entonces, anuncia ya que un cambio ha de producirse, y ese cambio comienza inmediatamente con las palabras que le siguen, aunque con una sutileza que sólo una disimulada anormalidad gramatical nos permite notarlo. $\mathrm{Y}$ aquí nos enfrentamos con una peculiridad sintáctica de las Odas seculares, cuyo estudio merecería un capítulo aparte. Por ahora nos limitaremos a este único ejemplo. En la estrofa se lee:

$$
\begin{aligned}
& \text {.. el paisaje } \\
& \text { retozado por yeguas que se azoran... }
\end{aligned}
$$

Se trata de una oración pasiva - desde un punto de vista lógico es una pseudopasiva, si esta categoría puede ser aceptada por la gramáticaconstruida con un verbo intransitivo que no admite complemento directo. La traslación activa, y por lo tanto imposible, seria: "Las yeguas retożan: el paisaje". Esta anormalidad gramatical es, sin embargo, un significativo 
rasgo de estilo. El poeta se ha propuesto la inmovilización del cuadro, que culminará con la imagen final del toro, y comienza por convertir en pasivo el sujeto paisaje; le resta toda dinámica posible al hacerlo paciente y agente activo. La congelación comienza, entonces, a producirse por una audaz maniobra en la utilización artística del lenguaje.

Si dijéramos: las yeguas retozan el paisaje (el campo) o su versión normal: las yeguas retozan en el paisaje, los dos términos (yeguas, paisaje) estarían estremecidos de un mismo movimiento, sería una visión claramente objetiva. Pero el poeta, en su camino hacia la fijación final, moviliza subjetivamente uno de los términos: paisaje, que se convierte en un fondo estático donde todavía se mueven los animales. $\mathrm{Y}$ hay algo más. Las oraciones subordinadas, referidas a yeguas - las cabezas tornan, etc.- y la metáfora del viento como una rienda, van frenando gramatical y psicológicamente el movimiento del cuadro. Así llegamos a los dos últimos versos de la estrofa, en donde todo el proceso de inmovilización ha llegado al estatismo total. $Y$ es ésta la segunda etapa que anteriormente hemos caracterizado como la de fijación del movimiento de la mirada en un punto determindo del paisaje. Pasamos ahora a la tercera: un brusco acercamiento del ojo - primer plano- a ese punto y su descripción detallada y morosa.

Estamos frente a la siempre recordada descripción del toro.

Una sangre excelente engarza su ojo

con bravío coral. Fuego de aurora

parece que se atarda purpurando

en su tostada piel...

El acercamiento es tan próximo que el ojo no alcanza a abarcar todo el animal, sino detalles de su conjunto: en estas líneas, el ojo del toro con el pormenor cromático de la esclerótica enrojecida por la irrigación capilar. La descripción colorística, pictórica, con que se inicia la estrofa se organiza enseguida en volumen escultórico:

$$
\text { ...su poderosa }
$$

fábrica funda en sus enjutos remos una gravedad brusca y categótica. $Y$ los vastos cuadriles y los flancos que así parece ponderar la norma del muto racional, y el rudo pecho que en la crasa marmella se desborda, acumulando en la cerviz su fuerza como en un tronco de coraje, aploman al macizo trapecio de la testa donde es padrón de raza el asta corta. 
Fuerzas, tensiones, equilibrios, erigen la imagen estatuaria del toro inmóvil, y con ella hemos llegado al grado máximo del objetivismo lugoneano. El conjunto, la fábrica del animal, está visto con ojo de pintor, de escultor, $\mathrm{y}$ aún diríamos de arquitecto que calcula pesos y fuerzas.

La segunda parte de la descripción del toro pertenece a otra estrofa, y en ella comienza ya a agitarse un movimiento en la figura:

$$
\text { en su nariz la estabular argolla... }
$$

estremecimiento que se va acentuando progresivamente:

\section{Soplos de brisa matinal le barren} con tibia suavidad la crespa cola.

Es un soplo de brisa que apenas mueve la cola del animal; pero enseguida toda la estructura plástica se sacude con el hondo mujido que abre dinámicamente a todo el paisaje y a todo el poema:

$$
\begin{aligned}
& \text { El mujido remoto y entrañable } \\
& \text { que su viril profundidad prolonga. }
\end{aligned}
$$

El adjetivo remoto, en su carga de distancia, el sustantivo profundidad, que también alude a espacio, y el verbo prolonga, que recibe, acumuladas, las direcciones signficativas de las palabras anteriores, son los factores de csta apertura y del alejamiento vertiginoso de la cámara hacia lo panorámico. Lo prueba el primer verso de la estrofa siguiente:

Piérdese el tren por los desicrtos campos...

La repetición anafórica del adverbio locativo allá, confirma el ya ininterrumpico desplazamiento de la mirada:

$$
\begin{aligned}
& \text { Allá el torito que con duro gesto... } \\
& \text { Allá el buey de las sólidas tareas... } \\
& \text { Allá la vaca fértil como el campo... etc. }
\end{aligned}
$$

Nos hemos demorado tal vez demasiado en esta primera parte, porque queríamos of recer una muestra del mentado objetivismo de la oda, de la peculiar estética del ojo lugoneano.

Sin embargo no todo en ella es un catálogo de visualidad, un alarc̀e plástico... Su composición es mucho más rica. A riesgo de caer en sim- 
plista esquematismo, podríamos postular dos planos: un plano objetivo, $A$ (con todas las reservas que hemos estado haciendo) y otro subjetivo, $B$. Estos planos no siempre permanecerían incomunicados, sino que muchas veces se cortarían, se rozarian tangencialmente, se integratían.

\section{EL PLANO OBJETIVO}

Ya hemos dicho bastante de él. Agregamos: en la oda predomina un estilo sustantivo, en cuanto está constituido por cosas, animales, plantas, personas presentados a través de una elaboración estética, en su más espléndida epifanía fenoménica. Sin embargo, y contra toda lógica aparente, no es el sustantivo gramatical el elemento fundamental de ese estilo, sino su aparente servidor: el adjetivo. Lugones fue uno de los primeros poetas modernos de lengua castellana que dignificó el adjetivo otorgándole un poder creador. En el poema que estamos estudiando, tiene un incalculable signo revelador del objeto. Este es arrancado de su alveolo convencional y proyectado singular, bautismalmente a una dimensión inédita.

La siempre censurable estadística nos resultará útil en esta ocasión. El epíteto, es decir el adjetivo que no singulariza, que simplemente explica una de las notas constitutivas del sustantivo adyacente, se anota en una proporción muy reducida frente al adjetivo recreador del objeto. No sucede lo mismo en toda la tradición geórgica que hemos considerado.

En Salazar de Alarcón, por ejemplo, vemos al emitible epíteto como única forma adjetiva:
Alli el bermejo chile colorea, y el naranjado aji no muy maduro... etc.

También en Bernardo de Balbuena, hablando del caballo;

...y el tostado alazán, que sin desgaire...

...el negro overo

y Bello

...su blanco pan la yuca

sus rubias pomas la patata educa...

- Bermejo chile, naranjado ají, tostado alazán, negro endrino, blanco pan, rubias pomas, y así, agotadoramente, el epíteto geórgico - pinguis bortos, tristis biems, pallentisque ederas - llega a lo largo de su discurso 
secular, hasta la modernidad de Lugones, pero para perder, esta vez, su antes decisiva importancia. $Y$ es que la interpretación genérica de la naturaleza americana, connatural con el espíritu del clasicismo, cede lugar a una consideración más inmediata y particularizadora del objeto. De ahí resulta esa sustantividad del estilo lugoneano y el papel creador que en él tiene el adjetivo usado como revelador y fortificador de la común significación del nombre, y no como obturador de su esplendor fenoménico. Leemos al azar: oro púber, luz copulativa, calores sonoros, agua eléctrica, pacíficas trenzas, nudoso ternero, etc.

Corresponde aquí señalar un aspecto estilístico curiosamente peculiar en el juego del adjetivo lugoneano de las "Odas". Y es el que llamamos, hace ya algunos años cuando por primera vez nos llamó la atención, contaminación sintagmática. Posteriormente, al conocer la Tieoría de la expresión poética de Carlos Bousoño, encontramos la descripción y estudio de casos aproximados, que el teórico español llama desplazamientos calificativos y que considera específicos de la poesía contemporánea, ya que señala su primera aparición en Juan Ramón Jiménez. Queda pendiente el examen cronológico que otorgue la verdadera primacía.

Elegimos de las "Odas" uno de los varios ejemplos del procedimiento:

Y el nudoso ternero se alborota, mientras que con desgano de bostezo

le brama la lechera cavernosa

Lechera cavernosa. La realidad no permite la adjudicación del adjetivo "cavernosa" a la lechera. Pero su sonido tiene un timbre que puede ser definido como cavernoso.

La contigüidad sintagmática hace, no que haya un simple desplazamiento calificativo, es decir, que lo cavernoso pase del sonido a la persona, sino que todo el verso, el verbo y el sustantivo, se contaminen de esa cualidad.

Por relación de contigüidad, por pertenecer al sintagma, el adjetivo destiñe su plasma significativo en todas las palabras que lo acompañan. En el libro mencionado, Bousoño explica el procedimiento por la necesidad de la poesía de anular la naturaleza analítica de la lengua y por el avance del irracionalismo en la poesía contemporánea. En nuestro caso concreto, es visible la prieta síntesis creadora del verso que en una sola línea reúne lo que la lengua - la prosa- tendría que explicar en tres o cuatro proposiciones. Señalamos, ahora, la presencia del hecho estilístico, y queda para más holgada ocạsión su detallado estudio. 
Pertenece también a este plano objetivo la escená, o sea la interpolación de cuadros con hombres en movimiento. La descripción encadenada de animales y plantas deja lugar al ingreso de personas en el marco, y aparece la escena familiar o pucblerina: un breve boceto donde el hombre se desplaza, se mueve y aún habla en medio de su circunstancia rural. Asi el paso afectuoso internacional del ruso Elías y el tưrco buhonero, la visita de los inmigrantes italianos al pueblo, la muchacha que da de comer a las gallinas. La escena, por su naturaleza estrictamente visual, pertenece integramente a lo alienado del sujeto. Está más cerca de la poesía épica, del teatro, del cinematógrafo, que de la poesía lírica.

Algunas escenas se acercan peligrosamente al teatro, y es cuando las personas se convierten en personajes y bablon. El diálogo, que en varias ocasiones trae tonos del sainete, que para aquel entonces ya había ganado la escena nacional; es también un elemento fortalecedor de ese plano externo. Dos personajes dialogan, y el poeta consigna textualmente lo escuchado, aproximándose de tal modo al más directo realismo:

$$
\begin{aligned}
& \text {-Que querés Don Ramírez... la crigolla } \\
& \text { e molto confortévole... }
\end{aligned}
$$

Pero es necesario el diálogo para ese testimonio de veracidad objetiva que en una de sus perspectivas pretende la "Oda". Basta la voz humana, no la interesada modulación interior, sino la simple voz del otro, de la tercera persona que no pertenece al diálogo, para sentirnos instalados en una circunstancia concreta, de gentes al alcance de nuestra mirada y de nuestros oídos, pero que además están por sí mismos allí, en un universo que compartimos en solidaria pero separada unidad:

$$
\begin{aligned}
& \text { Y a poco rato el padre, confirmando } \\
& \text { la resignación grave de sus horas, } \\
& \text { ampliaba el parecer de la consorte } \\
& \text { con palabras escasas y juiciosas: } \\
& \text { - Allá por el 63, en tiempo } \\
& \text { de Mitre... }
\end{aligned}
$$

Y aquí tocamos una de las facetas más discutidas del poema: el prosaísmo.

Dice Guillermo G. Ara, en su ya citado libro sobre Lugones: "E1 noble afán de no olvidar ningún elemento integrador del paisaje ni del panorama humano lo obliga a la inserción de instancias vulgares en la idea y de ingratos prosaísmos en la expresión". " Jorge Luis Borges ya se ha-

4 G. Ara, Op. cit. 106. 
bía anticipado en la respuesta: "No faltan prosaísmos deliberados, que responden al deseo de probar que todo cabe en la obra del poeta y que éste debe medirse con cualquier tema. Tal es la verosimil explicación de versos como éstos:

$$
\begin{aligned}
& \text { Reclamemos la enmienda pertinente } \\
& \text { del código rural cuya reforma } \\
& \text { en la nobleza del derecho agrícola } \\
& \text { y en equidad pecuaria tiene normas. }
\end{aligned}
$$

Hasta aquí Jorge Luis Borges. Lejos de ser censurable la adecuada inserción del prosaísmo, debemos entender que su presencia vitaliza la imagen del mundo exterior que el autor quiere of recernos. Desde Baudelaire, y aún antes, el prosaísmo es un elemento de fertilísima vitalidad estilística y su presencia en el poema, lejos de significar un descenso en la tensión espiritual, obedece a necesidades expresivas de la composición. No sólo los pasajes célebres fustigados o perdonados por los críticos componen el tejido prosaico de las "Odas". Una histología estilítica nos permitiría delimitar numerosas áreas de realismo doméstico o de praxis vital que, proveniendo de un declarado oficiante de la "tranche de vie", acaso entusiasmaran a más modestos cultores de "las cosas como son". Así, todo lo referente a la cocina criolla, a las industrias rurales y caseras, al funcionamiento de máquinas, al alza y la baja de valores, a las noticias del diario, etc.

Cabe señalar, también en este plano que estamos considerando, un aspecto que, según creemos, no ha sido todavía destacado.

Lugones, frente a la naturaleza, pese al ímpetu celebratorio de la "Oda", no adopta una actitud de lirismo hímnico, de entusiasmo vocativo. Hay una invitación al himno, pero el poeta se abstiene de la efusión lírica porque, en todo aspecto del poema, predomina su visión objetiva del mundo agrario:

Alcemos cantos en honor del trigo...
Cantemos al maíz cuyo tesoro...
Alabemos al lino que florece...
Conmemoremos la feraz promesa... etc.

Esta plural invitación al himno que en tal se queda, pues enseguida la descripción ahoga el conato lírico, no proviene de la tradición ameri-

5 Jorge Luis Borges, Leopoldo Lugones (Buenos Aires: Ediciones Troquel, 1955), p. 35 , 
cana que hemos señalado. Su remoto origen creemos que está en las geórgicas mismas. Dice Virgilio en el Libro II de las Geórgicas:

Ergo rito suum Basche dicemus honorem carminibus Patriis

El movimiento vocativo o hímnico, que significa un compromiso o una participación hondamente subjetiva, no se concilia con el ser en sí del mundo exterior que se está tratando de mostrar. El himno queda en la intención y la oda continúa en su fluir descriptivo.

Ahora bien. Toda esta materia de realismo que hemos anotado sumariamente ¿Cómo actúa, cómo se presenta en el cuerpo del poema? ¿Es el realismo el plasma único de la oda? Ya hemos dicho, al comienzo, que la memoria, el saber, las intuiciones anteriores del poeta, engarzan, en un halo de interioridad, las directas expresiones realistas. Hay una visión objetiva precisa, sí, pero su naturaleza no es la fotográfica, aunque a veces hablemos didácticamente de "cámaras". Es lo que, cuidando mucho las palabras, podríamos llamar "realismo mágico".

Un objeto, un hecho de ofensiva, de maciza, de contundente vulgaridad inmediata, es proyectado por el arte poético a una pantalla de suprarrealismo estético:

...Y al pálido alabastro que congela

en el puchero la trivial mandioca.

Mandioca, y especialmente puchero, por sus connotaciones, se inscriben en lo más cotidiano, material, orgánico y aún excusado de nuestro mundo vivencial; sin embargo, se encuadran en una categoría estética, son artísticamente arrebatados a su cotidianeidad por el estilo. El pálido alabastro de la más rigurosa estirpe modernista, los traslada, los transforma en objetos independientes, en naturaleza lírica.

Los grados de "artifización" entre las vertientes realística normal - puchero- - y la estéticamente enmarcada - pálido alabastro- son muy variados. A veces hay apenas un ascenso en la dignidad ontológica del objeto, como cuando leemos:

$\mathrm{y}$ digamos del ristico poroto

que hincha sus granos de ordinaria loza.

Hay un ascenso en el valor que va del objeto vulgar producido ciegamente por la naturaleza al objeto conformado por el hombre, lo cual supone un arte, por primario que este sea. 
Las variaciones en este sentido son numerosas. En estos ejemplos, y siempre dentro del plano objetivista que estamos considerando, los grados. $A$ y $B$ están expresados separadamente; los podemos aislar separándolos del contexto, y cada uno sigue persistiendo en su respectiva esfera. Pero hay momentos en que la integración se produce de tal modo que en un grado ya está el otro; son ya la misma cosa.

Voy a citar un ejemplo tomado de la estrofa en que se hace el elogio del asado:

la costilla florece de gordura...

Costilla y gardura por un lado (A( y el verbo florear (B), con su halo semántico que alude a jardín, a color, a perfume. No hay aquí un ascenso de lo material a su proyección estética, sino más bien una caida, una instalación de ésta en la materialidad que cede, concede y se transfigura.

Vemos, pues, que esta ladera del objeto no obedece, con rigidez, a la ortodoxia del realismo descriptivo. Pero hay algo más. Otro mundo, lírico, íntimo, que escapa ya abiertamente a la tradicón geórgica.

Por comodidad, por contraposición al anterior, hablaremos de un plano subjetivo. Algo intuyó Carlos Obligado cuando, refiriéndose a este poema, dijo: "Y es que el procedimiento descriptivo y la manera impersonal no impiden a esta oda ser lírica por cierto modo: la Patria floreciente es, en efecto, su numen superior. Además, la intención lírica circunstancial quebranta no pocas veces la mentada objetividad de tal poesía....".

Cuando creemos que Obligado va a acertar, vemos que ha pasado muy cerca del blanco sin ver el planteo a fondo. Al final reduce todo a que Lugones, en la descripción del sufrido caballito criollo, "se ahonda de emoción cariñosa". (Son sus palabras).

\section{EL PLANO SUBJETIVO}

La primera persona - sujeto de todo lirismo - aparece al finalizar el primer tercio de la oda, que está compuesta, en su totalidad, por unos mil quinientos versos. Todo ese fragmento inicial de casi quinientas líneas es el de más patente, regular y sostenido objetvismo descriptivo. Los indicios estilísticos del cambio no se han presentado todavía.

6 Carlos Obligado, La cueva del fósil (Buenos Aires: Librería La Facultad, 1927), p. 147. 
El poeta entra carnalmente en la oda a través de la posesión de su paisaje natal, y el ojo anónimo que registraba el encadenamiento plástico de cultivos, animales y hombres desde su mirador móvil, comienza a colorearse de significados psicológicos, de repertorio interior y memorioso en su contemplación ya interesada.

En las cañadas de mi sierra verde...

comienza, y desde este momento, el franco objetivismo de uno de los planos alternará, se cruzará o coexistirá con la valoración subjetiva de seres, de cosas, de hechos del otro plano correlativo. Esto, en progresión cada vez más acentuada, irá invadiendo todo el poema hasta los versos finales, donde se nos of recerá la clave de lo que consideramos como "biplanismo 'estético".

A esta toma de posesión de un paisaje propio corresponde inmediatamente una modificación reveladora en la conducta verbal del poema. A cada aparición del mundo personal, interior, del poeta, corresponderá una alteración en los tiempos y en las personas verbales. El presente de indicativo, instrumento de la descripción actual - Un verde matinal dora los compos- es inesperadamente sustituido por el imperfecto:

$$
\begin{aligned}
& \text {...con caballos y todo nos perdíamos } \\
& \text { en las chacras sonoras, } \\
& \text { buscando las espigas que manchaba } \\
& \text { una coloración morada o roja. }
\end{aligned}
$$

La retina ya no ve, ahora y aquí; el vasto y prodigioso escenario de la naturaleza presente ha desaparecido. La retina es ahora un instrumento de la memoria, y el lenguaje, en su maravillosa acomodación a los más sutiles movimientos del espíritu, encuentra en las resonancias emocionales del pretérito imperfecto nostálgico, la expresividad justa y profunda. Hasta este momento han predominado los aspectos sensoriales, pero desde ahora y en adelante comienza una hegemonía de la efectividad que se manifestará claramente denunciada en los indicios de estilo. El pretérito imperfecto, tiempo de la evocación morosa —el indefinido no conlleva nostalgia - aparece cuando el poeta, que ya se acerca a sus cuarenta años, penetra con su vida personal en la lujosa decoración terrestre de la oda. $Y$ casi con rigor de ley, a cada interpolación subjetiva en el lienzo descriptivo del poema, reaparecerá este imperfecto con su profunda gravidez de tiempo, vivencialmente asumido por quien recuerda, no lo que simplemente fue, sino lo que vivía, lo que era en su goteo mortal de cada segundo. 
Otra modificación verbal -dejamos para otro estudio la significación que cargan estilísticamente el infrecuente pretérito indefinido, un lírico futuro de deseo, etc.-, es la del cambio de persona. La descripción normal exige una tercera, separada del interés emotivo del artista; y esta tercera persona es la que, desde luego, acumula figuras e imágenes, en las vastas áreas visuales de la "oda". En esta cartografía subjetiva que estamos tratando de interpretar, la primera persona posesiva aparece como proceso normal de interferencia del yo en un ámbito ajeno. Pero hay otra persona también: el tú, el tú entrañable que desde el fondo del tiempo perdido, desde la irrecuperable juventud, regresa ahora, aquí, no como una figura que en su tiempo aparece en la cadena melancólica del recuerdo, sino como una materialización actual de lo que no regresará nunca. $Y$ no basta ahora el pretérito imperfecto de la evocación nostálgica. El tiempo es abolido, su fluencia se abre y se cierra en límites estrechos y precisos, la eternidad dura pocos instantes. Dice el poeta:

Vas una suave tarde con tu novia...

Pero esa segunda persona no es la del otro, la de un prójimo cercano; es la del poeta mismo, el propio Lugones que se mira a sí mismo veinte años atrás, como en una vieja fotografía de sepia sentimental.

Dos elementos se conjugan en este nudo de tensión estilística: uno, ese presente de indicativo que no queremos llamar ni histórico ni narrativo y que está muy lejos del habitual presente descriptivo de la oda, y otro, esa segunda persona que sustituye y duplica mágicamente a la primera, al yo conmovido.

El poeta va con su novia -fue hace ya muchos, ay!, irremediables años - hasta el establo para que la muchacha enferma - "está más delgadita de quererte", se dice a sí mismo veinte años después el poeta-, beba un vaso de leche recién ordeñada, y la pequeña égloga se cierra con una infantil, enternecedora sonrisa:

\footnotetext{
$Y$ en su puerilidad de alma dichosa

la niña te sonríe con los ojos

al ocupar sus labios en la copa.
}

Hay un profundo lirismo dramático en esa segunda persona, sustituyente gramatical del yo explícito. El poeta se ve a si mismo proyectado en una felicidad antigua, se reconoce en otro rostro juvenil que ya no es su rostro, en un momento que no retornará jamás, y otra vez el lenguaje 
quiebra su estructura habitual, y el rasgo de estilo, esa persona inusitada, revela el movimiento de las recónditas fuentes del ser.

Lo que parecía una oda apolínea, las geórgicas argentinas, a través de la égloga, comienza a acercarse, sin llanto, a la elegía.

Sin apartarnos de las formas verbales - las únicas por otra parte que consideramos - vamos a señalar, aunque sólo al pasar, otro aspecto significativo: lo que puede llamarse plural indeterminado de compañia, plural amistoso o entrañable, y que también, como en los casos anteriores, aparece inesperadamente en los momentos en que la subjetividad del poeta se manifiesta.

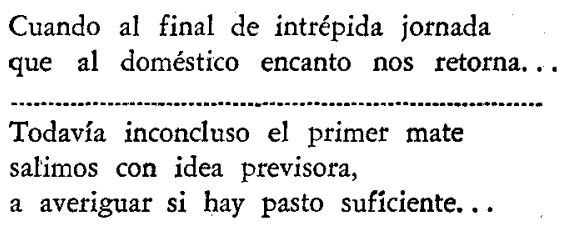

Nos retorna, salimos. Sin nada que lo anticipe, inesperadamente encontramos al poeta participando en una comunidad solidaria, afectiva. No se trata ya de mirar, de anotar, de censar poéticamente. . Ya no le interesa of recer a un lector desconocido un repertorio de cálidas imágenes rurales. Ahora se habla a sí mismo, se recuerda en medio de una amistad que ya fue; por eso no necesita dar nombres, porque todos están reunidos en ese plural afectivo que incluye al narrador y a sus para nosotros anónimos acompañantes de entonces, abrazados entrañablemente en la forma verbal. Así, un proceder habitual de la gramática, en su inserción inesperada en medio de una fluencia verbal que no lo requería, se carga de un inmenso poder de emoción que compromete la seguridad objetiva del poeta.

Muchos otros procedimientos de estilo -el diminutivo, la adjetivación emotiva, la adjetivación adverbial, las imágenes sentimentales de libros anteriores, la metáfora insólita, etc.- podríamos señalar en este avance de la interioridad sobre la naturaleza y la descripción, pero nuestro examen se ha hecho ya demasiado extenso y corresponde darle punto final. Una conclusión podemos, por lo menos, establecer, después de todo lo dicho: la "Oda a los ganados y las mieses", lejos de ser un poema exclusivamente descriptivo, como su inscripción en la tradición geórgica americana demandaría y como algunos críticos lo creyeron, es -en sus momentos de más alta tensión poética - un poema lírico que se expresa a través de la égloga y que por el camino del recuerdo se acerca a la elegía nostálgica. 
En las estrofas finales comprendemos el por qué de estas dos caras, de esta bifrontalidad que enriquece las perspectivas, las líneas de tensión del poema. Creo que todos recordarán la evocación de la madre, del padre, de los hermanos, de un remoto 25 de mayo de la infancia del poeta, con que se cierra:

Como era fiesta el día de la Patria, $y$ en mi sierta se nublan casi todas las mañanas de mayo, el 25 nuestra madre salía a buena hora de paseo campestre con nosotros...

y enseguida:

Embellecía un rubio aseado y grave sus pacificas trenzas de señora...

y luego, siempre refiriéndose a la madre:

Aunque aquí vaya junto con la Patria toda luz, es seguro que no estorba.

Adelgazada por penosos años, como el cristal casi no tiene sombras. Después, se nos ha puesto muy anciana, y si muere, sería triste cosa que no la hubiese honrado como debe su hijo mayor por vanidad retórica.

y más adelante, los versos finales correspondientes a la misma escena:

$Y$ mientras nos contaba todo aquello

el buen padre jovial nos daba escolta.

Montando por delante al más chiquillo que pedía galope a rienda corta, el andar de la bestia mantenía paralelo a la senda donde toda la familia marchaba de regreso al mismo paso y en la misma forma

y termina:

Así en profunda intimidad de infancia, el día de la Patria en mi memoria vive a aquella dulzura incorporado como el perfume a la hez de la redoma. 
Desde esta perspectiva final se ilumina ahora toda la estructura combinada del poema. Borges habla de "la tenacidad prolijamente enciclopédica que induce a Lugones a versificar todas las disciplinas de la agricultura y la ganadería", y agrega: "Felizmente hay confidencias personales que mitigan el fastidioso catálogo".

Carlos Obligado, ya lo vimos, sospecha elementos líricos, pero no precisamente en la entraña del poema, sino en lo accidental. En el libro de Guillermo Ara encontramos esta única referencia: "En la nota lírica, el atesorado recuerdo familiar se asienta en versos de factura limpia y de ubicación justa".

En el inteligente y olvidado libro de Juan Más y $\mathrm{Pi}^{7}{ }^{7}$ este aspecto es pasado por alto. Roberto Giusti, en 1911, es terminante: "La Oda' 'está sólo en el tono inicial; luego sigue la descripción con exclusión de todo otro elemento lírico". 8

Sin embargo esos versos finales son esclarecedores del ambivalente movimiento del poema. Recordemos lo ya dicho: desde el final de su primer tercio, la composición nos irá mostrando dos rostros alternativamente. Desde ese momento, la impasibilidad descriptiva comienza a conmoverse por ráfagas, primero apenas perceptibles, luego cada vez más arrebatadoras, de sentimiento y memoria personal. El feliz orden exterior de las cosas en paz consigo mismas y con el hombre; la epifanía épica de la naturaleza que debía exaltarse en versos de óptica grandeza o de salutación vocativa, son turbados por una agitación que proviene del yo, por el subjetivismo del tiempo existencial que se instala en los intersticios del universo visual y comienza a presionar en una expansión cada vez más poderosa, sobre su certeza y seguridad, sobre su actualidad, hasta abolirlo líricamente. Lugones, que quiere mostrar este mundo agrícola de aquí y de ahora, paulatinamente se convierte en el cantor de la perdida Edad Dorada, del tiempo mejor que ya fue. $Y$ éste es el secreto de las Odas seculares, que sólo encontrarán su culminación, casi treinta años después, en la valoración ética de las primitivas costumbres criollas anteriores a la inmigración, en sus Romances del Río Seco.

Así, las Odas seculares consignan y alaban una actualidad de riqueza y de paz, pero por su entraña poética corre un estremecimiento que las conforma líricamente y que proviene del sentimiento profundo del pasado irrecuperable. $\mathrm{Y}$ el secreto está en estos últimos versos:

7 Juan Más y $\mathrm{Pi}$, Leopopoldo Lugones y su obra (Buenos Aires: Ediciones Reracimiento, 1911 ).

s Roberto F. Giusti, Nuestros poetas jóvenes (Buenos Aires: Nosotros, 1911). 
Así en profunda intimidad de infancia el día de la patria en mi memoria vive a aquella dulzura incorporado.

El trémolo, pues, perturbador, de la impecabilidad descriptiva está en los recuerdos infantiles. Ellos son los que fracturan la epicidad descriptiva de la oda que, por "vanidad retórica", debió haber mantenido. Ellos son los que hacen de la "Oda a los ganados y las mieses" un intenso poema de amor, y no un censo retórico de ganados, de mieses, de solidarios gringos y de metáforas felices.

Universidad Nacional de Cuyo, ALFONSO SOlA GONZÁlez Mendoza, Argentina 